\title{
Relationship of Biological Markers of Body Fat Distribution and Corticosteroidogenic Enzyme Activities in Women with Polycystic Ovary Syndrome
}

\author{
Authors \\ Sebastião Freitas de Medeiros', ${ }^{1,}$, Matheus Antonio Souto de Medeiros², Bruna Barcelo Barbosa², \\ Márcia Marly Winck Yamamoto ${ }^{2}$
}

Affiliations
1 Department of Gynecology and Obstetrics, Medical
School, Federal University of Mato Grosso, Mato Grosso,
Brazil
2 Tropical Institute of Reproductive Medicine, Cuiabá, MT,
Brazil

Key words

sex steroids, hyperandrogenism, steroidogenesis

received 25.02.2019

accepted 11.07.2019

Bibliography

DOI https://doi.org/10.1055/a-0975-9207

Horm Metab Res 2019; 51: 639-648

(c) Georg Thieme Verlag KG Stuttgart · New York

ISSN 0018-5043

Correspondence

Sebastião Freitas de Medeiros MD, PhD

Tropical Institute of Reproductive Medicine

Cuiabá, MT

Rua: Almirante Henrique Pinheiro Guedes, № 195

78.043-306 Cuiabá

Mato Grosso

Brazil

Tel.: + 55/65/3322 2017, Fax: + 55/65/999810474

de.medeiros@terra.com.br

\section{ABSTRACT}

The aim of the study is to determine the impact of different anthropometric measurements of fat distribution on baseline sex-steroid concentrations and corticosteroidogenic enzyme activity in women with polycystic ovary syndrome compared to those with regular menstrual cycles. The current cross-sectional study included 106 normal cycling controls and 268 polycystic ovary syndrome patients. Patients with polycystic ovary syndrome, diagnosed by Rotterdam criteria, were divided in normoandrogenemic $(n=91)$ and hyperandrogenemic $(n=177)$. Anthropometric, biochemical, and hormone parameters were assessed and correlated with corticosteroidogenic enzyme activities in all three groups. Corticosteroidogenic enzyme activities were calculated using product-to-precursor ratios. Regarding sex-steroids individually, anthropometric parameters correlated with the concentrations of several androgens in polycystic ovary syndrome patients, most of them in patients with biochemical hyperandrogenism. The androgen precursors androstenedione, 17-hydroxyprogesterone, and dehydroepiandrosterone were less correlated with anthropometric parameters. The 17,20 lyase activity, in both $\Delta 4$ and $\Delta 5$ pathways, correlated with several anthropometric measurements in normo- and hyperandrogenemic polycystic ovary syndrome patients. The 17,20 lyase enzyme activity ( $\Delta 4$ pathway) also correlated with conicity index, visceral adiposity index, and lipid accumulation product in the control group. 17-Hydroxylase activity positively correlated with waist-height ratio in both polycystic ovary syndrome groups. In contrast, 17-hydroxilase negatively correlated with the conicity index. Anthropometric markers of adiposity are associated with androgen levels and their precursors in blood. Body fat distribution correlates with the activities of some steroidogenic enzyme in both normo-and hyperandrogenemic polycystic ovary syndrome phenotypes. The molecular mechanisms involved in these associations are largely unclear and more investigations are required.

\section{Introduction}

Polycystic ovary syndrome (PCOS) is characterized by infrequent menses, amenorrhea, infertility, weight gain, dyslipidemia, dysglycemia, and hyperandrogenemia. PCOS patients with hyperandro- genemia may have a higher risk for cardiovascular disease (CVD) than those with normoandrogenemia phenotype [1]. Moreover, there is a strong association between androgens and their precursors and obesity [2]. Hyperandrogenism is also associated with the 
amount of fat localized in the trunk [3] and the administration of testosterone has been shown to increase visceral fat accumulation [4]. Therefore, hyperandrogenism may increase abdominal visceral adiposity in women and hyperandrogenemic PCOS patients are more likely to be obese [5].

Several anthropometric parameters have been used as markers for a higher risk of type II diabetes mellitus, and CVD, mainly when hyperandrogenism is associated with abnormal fat deposition [6]. Additionally, it was demonstrated that body mass index (BMI), waist circumferences (WC)/hip ratio (WHR), and conicity index (CI) have a strong correlation with total fat mass and central abdominal fat, as diagnosed with dual X-ray absorptiometry (DEXA) [7]. Visceral adiposity index (VAI) has recently replaced computerized tomography $(\mathrm{CT})$ as a surrogate marker for visceral adiposity in clinical studies [8]. In prepubertal and pubertal girls, progesterone (P4), 17-hydroxypregnenolone (17-OHPE), total testosterone (T), and androstenedione (A4) increase with obesity. VAI and fat mass (FM) seem to be positively correlated with $T$ [9], while WHR positively correlated with A4 [10]. In contrast, dehydroepiandrosterone (DHEA) seems to be negatively related to total and visceral adiposity in non-PCOS subjects [11].

The net effects of the degree or the distribution of adiposity on steroidogenic enzyme activities remain unclear. Adipokines were shown to modulate steroidogenic enzymes, such as the steroidogenic acute regulatory protein (StAR), P450 side chain cleavage en-

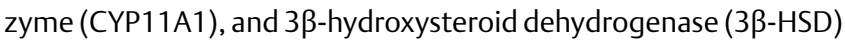
$[12,13]$. Further, adiponectin has been shown to reduce the production of A4 in theca cells [14]. Androgens increase visceral fat mass through the inhibition of lipolysis and the stimulation of lipogenesis [15]. Though the existence of individual variations in steroid levels in adipose tissue [16], it is less clear whether and to what extent the levels of these steroid hormones vary within the same individual. In vitro and in vivo studies suggest different steroidogenic capacity between abdominal adipose tissue and adipose tissue from other locations [17-20]. Further, 17 -hydroxysteroid dehydrogenase (17-HSD) activity in abdominal adipose tissue may favor visceral adiposity and metabolic syndrome [21]. The present study was designed to examine the association of different anthropometric parameters as surrogate markers of adipose tissue distribution with androgen concentrations and steroidogenic enzyme activities in PCOS. These possible associations were assessed between PCOS women with high androgen levels in blood, PCOS women with normal levels of androgen and, also in non-PCOS women with normal menstrual cycles.

\section{Subjects and Methods}

\section{Study design and subjects}

This cross-sectional study, using accessibility sampling, enrolled 268 patients diagnosed with PCOS using the Rotterdam criteria, and 106 normal cycling controls who presented to the Júlio Muller University Hospital and Tropical Institute of Reproductive Medicine in Cuiabá, MT, Brazil from January 2012 to June 2017. A specific signed informed consent approved by the local Committee for Ethics in Research was signed by each participant before data collection in the course of routine clinical assistance in both Institutions.
PCOS patients were divided in normoandrogenemic PCOS (NAPCOS, $n=91$ ) and hyperandrogenemic PCOS (HA-PCOS, $n=177$ ). NA-PCOS, HA-PCOS and normal cycling women were compared to assess whether they present differences in the corticosteroidogenic enzyme activities among them. According to several robust publications, biochemical hyperandrogenemic PCOS may be defined by the presence of one or more of the following biochemical parameters: $T \geq 2.1 \mathrm{nmol} / \mathrm{l}$, free $\mathrm{T} \geq 0.027 \mathrm{pmol} / \mathrm{l}, \mathrm{DHEA} \geq 6.7 \mu \mathrm{mol} / \mathrm{l}$, $\mathrm{A} 4 \geq 8.6 \mathrm{nmol} / \mathrm{l}$, and free androgen index (FAl) $\geq 6$ [22-25]. Patients who had used sex steroids or insulin sensitizing drugs over the last six months or who did not fulfill the Rotterdam criteria were excluded. In addition, patients with TSH levels $\geq 4.2 \mu \mathrm{IU} / \mathrm{I}$, prolactin $\geq 1.086 \mathrm{pmol} / \mathrm{l}$, and $17-\mathrm{OHP} 4 \geq 6 \mathrm{nmol} / \mathrm{l}$ were also excluded.

\section{Measurement of anthropometric characteristics}

The subjects were weighed on an electronic scale, and height was measured using a Harpender stadiometer (Holtain Limited, Crymych, Dyfed, UK). The waist circumference (WC) was measured at the midway point between the lower rib margin and the iliac crest, and the hip was measured at the widest circumference at the iliac crest. BMI was calculated as body weight $(\mathrm{kg}) /$ height $\left(\mathrm{m}^{2}\right)$. Lean body mass (LBM) was calculated using the James equation: [1.07 $\times$ weight $(\mathrm{kg})]-148 \times$ weight $(\mathrm{kg})^{2} /\left[100 \times\right.$ height $\left.\left(\mathrm{m}^{2}\right)\right]$ [26]. Fat mass (FM) was calculated as body weight minus LBM. Abdominal adiposity was estimated using the conicity index (C index): WC (m)/ $(0.109 \times$ square root of body weight $(\mathrm{kg}) /$ height $(\mathrm{m})$ [27]. The visceral adiposity index (VAl) was estimated using the equation: WC/ $[36.58+(1.89 \times \mathrm{BMI})] \times(\mathrm{TG} / 0.81) \times(1.52 / \mathrm{HDL}-\mathrm{C})[28]$. Lipid accumulation product (LAP) was calculated as established for women [WC (cm)-58) × TG (mmol)] [29].

\section{Biochemical and hormone analysis}

All patients with regular cycles were tested in the early follicular phase of the menstrual cycle (days 3-5 of the cycle). Patients with infrequent menses or amenorrhea had their blood collected at any time provided the progesterone was less than $6.4 \mathrm{nmol} / \mathrm{l}$. Triglycerides (TG), high-density lipoprotein cholesterol (HDL-C), and total cholesterol (TC) levels were measured using an enzymatic assay (Wiener Laboratories, Rosário, Argentina). Low-density lipoprotein cholesterol (LDL-C) was calculated as TC-(HDL-C + TG/5) [30]. Glucose concentration was analyzed using the glucose oxidase technique (Beckman Glucose Analyses, Fullerton, CA, USA). Impaired glucose tolerance (IGT), or prediabetes, was defined by a single abnormal parameter as follows: fasting plasma glucose (FPG) between $100 \mathrm{mg} / \mathrm{dl}$ (5.5 mmol/l) and $126 \mathrm{mg} / \mathrm{dl}$ (6.99 mmol/l); 2-hour oGTT glucose value between $140 \mathrm{mg} / \mathrm{dl}(7.8 \mathrm{nmol} / \mathrm{l})$ and $199 \mathrm{mg} /$ dl (11.0 nmol/I) [7]. Type II diabetes mellitus (T2DM) was defined as fasting glucose $\geq 6.99 \mathrm{nmol} / \mathrm{l}$ or over $7.8 \mathrm{nmol} / \mathrm{l}$ at $120 \mathrm{~min}$ after $75 \mathrm{~g}$ dextrose ingestion. Insulin resistance was defined using fasting insulin levels > $12.2 \mu \mathrm{U} / \mathrm{ml}$ (84.7 pmol/I) [26]; and/or homeostasis model assessment of insulin resistance (HOMAIR) $\geq 2.7$ [31]. The homeostatic model for insulin resistance and tissue sensitivity to insulin (HOMA-IR) was calculated using a free online program [32]: [glucose $(\mathrm{nmol} / \mathrm{l}) \times$ insulin $(\mu \mathrm{U} / \mathrm{ml})] / 22.5$. Oral glucose tolerance test (OGTT) was performed by measuring glucose before and 120 min after $75 \mathrm{~g}$ oral dextrose. All hormone measurements were detailed in a recent publication [33]. The level of 17-OHPE was 
measured with an HPLC/MS/MS (Labco Nous Advanced Special Diagnostics, SP, Brazil). The sensitivity was $0.033 \mathrm{nmol} / \mathrm{l}$, and intra-and inter-assay coefficients of variation were between $10.4 \%$ and $12.9 \%$, respectively. FAI was calculated as the $\mathrm{T}(\mathrm{nmol} / \mathrm{I}) / \mathrm{SHBG}$ $(\mathrm{nmol} / \mathrm{I}) \times 100$. Free estrogen index $(\mathrm{FEI})$ was estimated as $100 \times$ E2pmol/l/272.14 × SHBG [28].

\section{Statistical analysis}

Results are presented as percentages or mean $\bar{x}$ and standard deviation (SD) or number and percentage ( $\mathrm{n} \%$ ). Comparison of ethnicities was performed using the qui-square test. Proportions of IGT, IR, and HOMA-IR among groups were also compared using the qui-square test followed by the Dunn test with Bonferroni adjustments. Baseline differences between more than two independent continuous variables were assessed using one-way analysis of variance (ANOVA), followed by the Tukey post hoc and $\mathrm{F}$ tests. The re-

- Table 1 Comparison of clinical and anthropometric baseline characteristics of women with polycystic ovary syndrome and normal cycling non-PCOS women.

\begin{tabular}{|c|c|c|c|}
\hline Variable & $\begin{array}{l}\text { Normal } \\
\text { cycling } \\
\text { women }\end{array}$ & $\begin{array}{l}\text { NA-PCOS } \\
\text { group }\end{array}$ & $\begin{array}{l}\text { HA-PCOS } \\
\text { group }\end{array}$ \\
\hline Age (years) & $30.6(4.73)$ & $29.1(5.40)$ & $26.9(5.00)^{a, b}$ \\
\hline \multicolumn{4}{|l|}{ Ethnicity n (\%) } \\
\hline White & $85(80.1)$ & $119(71.7)$ & $70(76.9)^{\mathrm{NS}}$ \\
\hline Afro descendent & $14(13.2)$ & $26(15.7)$ & $10(11.0)^{\mathrm{NS}}$ \\
\hline Others & $6(5.7)$ & $21(12.6)$ & $11(12.1)^{\mathrm{NS}}$ \\
\hline \multicolumn{4}{|c|}{ Blood pressure $(\mathrm{mmHg})$} \\
\hline SBP & $112.9(9.3)$ & $114.4(13.1)$ & $118.3(10.9)^{\mathrm{a}, \mathrm{c}}$ \\
\hline DBP & $73.0(7.3)$ & $73.4(9.7)$ & $76.2(10.6)^{\mathrm{a}, \mathrm{d}}$ \\
\hline \multicolumn{4}{|c|}{ Anthropometric parameters } \\
\hline Body weight (kg) & $61.6(9.4)$ & $75.0(199.4)$ & $75.7(16.5)^{a, d}$ \\
\hline BMI $\left(\mathrm{kg} / \mathrm{m}^{2}\right)$ & $23.5(3.4)$ & $28.9(7.0)$ & $30.3(6.7)^{a, d}$ \\
\hline WC $(\mathrm{cm})$ & $73.5(8.3)$ & $86.3(15.0)$ & $88.2(14.6)^{\mathrm{a}, \mathrm{d}}$ \\
\hline WHR $(\mathrm{cm})$ & $0.75(0.06)$ & $0.80(0.07)$ & $0.82(14.6)^{\mathrm{a}, \mathrm{d}}$ \\
\hline $\mathrm{Cl}(\%, \mathrm{pg} / \mathrm{ml} . \mathrm{nmol})$ & $1.09(0.07)$ & $1.16(0.09)$ & $1.18(0.1)^{\mathrm{a}, \mathrm{d}}$ \\
\hline LBM (kg) & $43.42(4.44)$ & 46.92 (6.69) & $45.77(5.62)^{\mathrm{a}, \mathrm{e}}$ \\
\hline FM/LBM ratio & $0.41(0.11)$ & $0.59(0.22)$ & $1.80(0.73)^{b, c, d}$ \\
\hline FM (kg) & $18.18(5.88)$ & $28.57(13.92)$ & $29.71(11.96)^{\mathrm{a}, \mathrm{d}}$ \\
\hline VAl & $1.16(0.77)$ & $1.77(1.61)$ & $2.66(2.43)^{a, b}$ \\
\hline LAP & $14.65(12.90)$ & $32.82(28.62)$ & $52.25(48.62)^{c, d, f}$ \\
\hline
\end{tabular}

Data are expressed as mean and standard deviation $\bar{x}(S D)$ or $n(\%)$. ANOVA followed by Tukey post hoc test was used for continuous variables and $x^{2}$ test followed by Dunn test with Bonferroni adjustments for categorical variables. SBP: Systolic blood pressure; DBP: Diastolic blood pressure; BMI: Body mass index; WC: Waist circumferences; WHR: Hip ratio; Cl: Conicity index; LBM: Lean body mass; FM/LBM: Fat mass/ lean body mass ratio; FM: Fat mass; VAl: Visceral adiposity index; LAP: Lipid accumulation product. NS: $p>0.05$; a Control vs. NA-PCOS, $p<0.001$; ${ }^{\circ}$ NA-PCOS vs. HA-PCOS, $p=0.004$; c NA-PCOS vs. HA-PCOS,

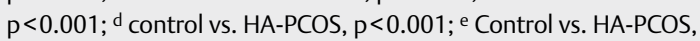
$\mathrm{p}=0.004 ;{ }^{\mathrm{f}}$ Control vs. NA-PCOS, $\mathrm{p}=0.003$. lationship between two Gaussian distributed variables was examined using the Pearson's correlation coefficient (r). Further, a stepwise-multiple linear regression analysis was performed to estimate the relationship between enzyme activity and anthropometric parameters. The product/precursor ratio was used as the criterion variable and anthropometric, endocrine, and metabolic variables that presented a simple significant correlation with the criterion variable were used as predictor variables. The Durbin-Watson test was used to verify correlation between residuals. All statistical procedures were performed with SPSS version 17 (SPSS Inc., Chicago, IL, USA). All tests were two-sided, and $p$-values $<0.05$ were considered statistically significant.

\section{Results}

\section{Baseline characteristics of normo- and hyperandrogenemic PCOS patients and normal cycling controls}

Ethnicity, clinical, and anthropometric features of each group are summarized in > Table 1. Regarding ethnicity, no differences were found among groups $\left(x^{2}=2.538, p=0.281\right)$. Blood pressures, both SBP and DBP, were higher in HA-PCOS group than in controls and NA-PCOS ( $p<0.001$, and $p=0.004$, respectively). BMI, WC, WHR, and $\mathrm{CI}, \mathrm{LBM}, \mathrm{FM}$, and LAP, variables commonly associated with higher risk for long-term disease, were significantly increased in HAPCOS patients when compared with controls and NA-PCOS groups ( $\triangleright$ Table 1). All data regarding carbohydrate metabolism are shown in $>$ Table 2. IFG had similar prevalence in controls and NA-PCOS (4. 1 vs. $4.5 \%$, respectively; $p=0.976$ ). In HA-PCOS patients IFG was more frequent than in controls and in NA-PCOS. In the whole group of PCOS, IFG was higher than in NA-PCOS and similar to HA-PCOS ( 12.3 vs. $15.9 \%, p=0.352$; data not shown).

Glucose intolerance (GI, glucose $\geq 7.8 \mathrm{nmol} / \mathrm{l}$ at 120 in TTOG) in the whole group of PCOS had a prevalence of $22.1 \%$. Other results regarding $\mathrm{Gl}$ are shown in $>$ Table 2 . Using the cut-off values of $84.7 \mathrm{pmol} / \mathrm{I}$, the insulin resistance was more prevalent in NAPCOS (43.9\%), HA-PCOS (57.8\%), and in PCOS as a group (52.4\%) than in controls $(12.8 \%)$ ( $p<0.001$ for all comparisons). Otherwise, NA-PCOS presented lower prevalence of IR than HA-PCOS $(p<$ $0.001)$, and than PCOS women as a group ( $<<0.001)$. The baseline levels of fasting insulin in all PCOS groups were significantly higher than in controls ( $\triangleright$ Table 2 ). In the control group, no women presented HOMA-IR over 2.7. HOMA-IR was $\geq 2.7$ in $10 \%$ NA-PCOS, $30.6 \%$ in HA-PCOS, and in $23.8 \%$ in the whole group of PCOS women. There were no difference in HOMA-IR between controls and NAPCOS women $(p=0.144)$. However, HOMA-IR was higher in HAPCOS than in controls ( $30.6 \%$ vs. $0 \%, p<0.001)$, NA-PCOS $(30.6 \%$ vs. $10 \%, p<0.001)$ and in the whole PCOS group ( $30.6 \%$ vs. $23.8 \%$, $\mathrm{p}=0.003)$. FPG, insulin, and HOMA-IR were also higher in HA-PCOS than in NA-PCOS. On the other hand, HOMA-S was lower in the NAPCOS and HA-PCOS groups. C-peptide was higher in NA-PCOS and HA-PCOS when compared with controls ( $\triangleright$ Table 2 ).

- Table 3 compares sex-steroids concentrations and steroidogenic enzymatic activities between normal cycling women and women with PCOS, either normoandrogenemic or hyperandrogenemic. Though E2 had been similar in all groups, FEI shows statisti- 
- Table 2 Comparison of baseline carbohydrate metabolic markers in women with polycystic ovary syndrome and non-PCOS women with regular menstrual cycles.

\begin{tabular}{|l|l|l|l|}
\hline Variable & $\begin{array}{l}\text { Normal } \\
\text { cycling } \\
\text { women }\end{array}$ & $\begin{array}{l}\text { NA-PCOS } \\
\text { group }\end{array}$ & $\begin{array}{l}\text { HA-PCOS } \\
\text { group }\end{array}$ \\
\hline FPG (nmol/l) & $4.7(0.5)$ & $4.8(0.4)$ & $4.9(0.5)^{\mathrm{a}}$ \\
\hline IFG (\%) & 4.1 & 4.5 & $15.9^{\mathrm{b}, \mathrm{c}}$ \\
\hline GI (\%) & 3.7 & 13.8 & $25.3^{\mathrm{a}, \mathrm{b}, \mathrm{c}}$ \\
\hline Fasting insulin $(\mu \mathrm{mol} / \mathrm{l})$ & $48.1(3.7)$ & $83.5(5.8)$ & $101.8(10.8)^{\mathrm{a}, \mathrm{b}, \mathrm{e}}$ \\
\hline HOMA-IR $\geq 2.7(\%)$ & 0 & 10.0 & $30.6^{\mathrm{a}, \mathrm{b}}$ \\
\hline HOMA-IR & $0.95(0.2)$ & $1.56(0.1)$ & $1.95(0.2)^{\mathrm{a}, \mathrm{c}, \mathrm{f}}$ \\
\hline HOMA \%B & $106.9(44.8)$ & $142.4(79.1)$ & $154.9(66.9)^{\mathrm{a}, \mathrm{g}}$ \\
\hline HOMA-S & $132.5(70.3)$ & $79.3(53.1)$ & $69.9(49.5)^{\mathrm{a}, \mathrm{f}}$ \\
\hline Pep-C (nmol/l) & $0.53(0.2)$ & $0.68(0.3)$ & $0.90(0.4)^{\mathrm{a}, \mathrm{d}, \mathrm{h}}$ \\
\hline
\end{tabular}

Categorical variables age given in proportions (\%) and continuous variables are given in $\bar{x}(S D)$. ANOVA followed by Tukey post hoc test was used for continuous variables and $x^{2}$ test followed by Dunn test with Bonferroni adjustments for categorical variables. FPG: Fasting plasma glucose; IFP: Impaired fasting glucose; GI: Glucose intolerance; HOMA: Homeostatic assessment model;

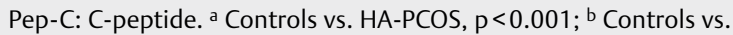
HA-PCOS, $p=0.008 ;{ }^{c}$ NA-PCOS vs. HA-PCOS, $p=0.007 ;{ }^{d}$ NA-PCOS vs. HA-PCOS, $p<0.001$; e NA-PCOS vs. HA-PCOS, $p=0.030$ ${ }^{f}$ Controls vs. NA-PCOS, $p<0.001 ; 9$ Controls vs. NA-PCOS, $\mathrm{p}=0.002 ;{ }^{\mathrm{h}}$ Controls vs. NA-PCOS, $\mathrm{p}=0.003$.

cally significant higher levels in NA-PCOS and HA-PCOS women than in controls ( $p<0.001$ and $p<0.001$, respectively). As expected, all androgen hormones were also higher in HA-PCOS women than in controls and NA-PCOS subjects. Regarding the enzyme activities, 17,20 lyase activity ( $\triangle 4$ pathway) was higher in HA-PCOS than in NA-PCOS and controls ( $p<0.001$ and $p<0.001$, respectively). 17hydroxilase activity $(\triangle 4)$ was higher in NA-PCOS and HA-PCOS than in controls $(p<0.0001$ and $p=0.025$, respectively). The $3-\beta H S D$ had higher activity in the conversion of DHEA into A4 in HA-PCOS and NA-PCOS groups ( $p<0.001$ for both comparisons). Further, 21-hydroxylase activity was lower in HA-PCOS than in normal cycling women $(p<0.001)$ and in NA-PCOS $(p=0.025)$. The combined activity of 21-hydroxilase and 11-hydroxilase was also lower in HAPCOS than in NA-PCOS and controls $(p<0.001$ and $p=0.015$, respectively).

\section{Simple correlation between anthropometric parameters and androgens concentrations}

Possible simple correlations between anthropometric measurements and a particular androgen concentration are summarized in this section. BMI presented a negatively and significant correlation with 17-OHPE in controls ( $r=-0.201, p=0.049)$. In NA-PCOS, BMI was negatively correlated with DHEA $(r=-0.245, p=0.033)$ but in HA-PCOS BMI was positively correlated with total testosterone $(r=0.199, p=0.010)$. WHR was positively correlated with total tes- tosterone in controls $(r=0.215, p=0.037)$, and negatively correlated with A4 $(r=-0.384, p<0.001)$, and DHEA $(r=-0.276, p=0.016)$ in the NA-PCOS group. On the other hand, in HA-PCOS WHR was negatively correlated with 17-OHPE $(r=-0.237, p=0.002)$. The WHtR was negatively correlated with 17-OHPE $(r=-0.201$, $p=0.048)$ in controls, negatively correlated with $A 4(r=-0.249$, $p=0.019)$ in NA-PCOS, and negatively $(r=-0.167)$ and positively $(r=0.116)$ correlated with 17-OHPE $(p=0.033)$, and total testosterone $(p=0.006)$, respectively.

The conicity index $(\mathrm{Cl})$ negatively correlated with $A 4(r=-0.249$, $p=0.027)$ in NA-PCOS and with 17-OHPE $(r=-0.175, p=0.027)$ in HA-PCOS. LBM was correlated only with A4 $(r=0.200, p=0.014)$ in the HA-PCOS group. FM was negatively correlated with 17-OHP4 $(r=-0.205, p=0.050)$ in controls and with total testosterone $(r=0.192, p=0.014)$ in HA-PCOS. LBM/FM ratio was negatively correlated with total testosterone in HA-PCOS $(r=-0.176, p=0.024)$. VAl was negatively correlated with 17-OHP4 $(r=-0.211, p=0.049)$ and positively correlated with $\mathrm{A} 4(\mathrm{r}=0.251, \mathrm{p}=0.020)$ in controls. In NA-PCOS VAI was positively correlated with 17-OHPE $(r=0.425$, $p<0.001)$, and negatively correlated with 17-OHPE $(r=-0.175$, $\mathrm{p}=0.036$ ) in the HA-PCOS group. Finally, LAP was positively correlated with 17-OHPE in NA-PCOS $(r=0.417, p<0.001)$, and negatively correlated with 17-OHPE $(r=-0.199, p=0015)$ in the HAPCOS group.

\section{Simple correlation between anthropometric measures and corticosteroidogenic enzyme activity}

Associations between anthropometric parameters and enzyme activities are shown in > Table 4. In both NA-PCOS and HA-PCOS patients, the $\Delta 5$ pathway 17,20 lyase negatively correlated with $\mathrm{Cl}$, and LAP, but in this $\Delta 5$ pathway, 17,20 lyase correlated positively with WHR in the HA-PCOS group. In controls 17,20 lyase $(\Delta 5)$ did not present correlation with any anthropometric measurement ( Table 4). In the $\Delta 4$ pathway in normal cycling women, 17,20 lyase activity was positively correlated with $\mathrm{Cl}$, VAI, and LAP. In HA$\mathrm{PCOS}$, this enzyme in the $\Delta 4$ pathway positively correlated with FM and the LBM/FM ratio.

In normal cycling women, 17-hydroxylase activity, in the conversion of P4 into 17-OHP4, presented a negative simple correlation with $\mathrm{Cl}$, but in HA-PCOS patients this enzyme was positively correlated with WHR. A non-significant trend was observed between 17-hydroxylase activity, body weight $(p=0.052)$ and BMI $(p=0.071)$ in the HA-PCOS group. In this HA-PCOS group, in the conversion of 17-OHPE into 17-OHP4, the $3 \beta-H S D$ activity was positively correlated with WC $(p=0.049)$ and WHR $(p=0.023)$ and negatively correlated with $\operatorname{VAI}(p=0.012)$. In NA-PCOS, 3 $\beta$-HSD activity also negatively correlated with VAI. In the conversion of DHEA into A4, 3B-HSD activity positively correlated with WHR in HA-PCOS patients and negatively correlated with WHtR in normal controls. In both NA-PCOS and HA-PCOS patients, the activity of 21-hydroxylase did not correlate with anthropometric parameters. On the contrary, in controls, $3 \beta-\mathrm{HSD}$ was positively correlated with BMI, WHtR, Cl, and LAP. 11 $\beta$-Hydroxylase also did not correlate with any anthropometric parameter in PCOS but was negatively correlated with WHR and $\mathrm{Cl}$ in normal controls. 
- Table 3 Comparison of endocrine characteristics between women with polycystic ovary syndrome and women with normal regular cycles.

\begin{tabular}{|c|c|c|c|}
\hline Variable * & Control $\bar{x}(S D)$ & Normoandrogenemic PCOS $\bar{x}$ (SD) & Hyperandrogenemic PCOS $\bar{x}$ (SD) \\
\hline P4 (nmol/l) & $1.54(1.02)$ & $1.21(0.78)$ & $2.10(1.10)^{\mathrm{NS}}$ \\
\hline E2 (pmol/l) & $181.85(99.32)$ & $179.61(82.84)$ & $191.81(79.18)^{\mathrm{NS}}$ \\
\hline FEI (\%) (ng/nmol) & $0.35(0.22)$ & $0.43(0.27)$ & $0.72(0.47)^{\mathrm{a}, \mathrm{b}}$ \\
\hline $\mathrm{T}(\mathrm{nmol} / \mathrm{l})$ & $1.00(0.54)$ & $1.11(0.39)$ & $2.34(1.08)^{\mathrm{a}, \mathrm{b}}$ \\
\hline fT $(\mathrm{nmol} / \mathrm{l})$ & $0.013(0.01)$ & $0.021(0.02)$ & $0.057(0.04)^{a, c}$ \\
\hline FAI (\%) & $2.14(1.90)$ & $2.59(1.36)$ & $8.87(5.81)^{\mathrm{a}, \mathrm{b}}$ \\
\hline $\mathrm{F}(\mu \mathrm{mol} / \mathrm{l})$ & $353.17(143.74)$ & $321.87(131.67)$ & $342.33(141.26)^{\mathrm{NS}}$ \\
\hline A4 (nmol/l) & $5.20(2.39)$ & $4.96(1.91)$ & $10.39(5.104)^{\mathrm{a}, \mathrm{b}}$ \\
\hline DHEA (nmol/l) & $15.23(8.41)$ & $14.98(8.68)$ & $18.01(10.31)^{a, b}$ \\
\hline DHEAS $(\mu \mathrm{mol} / \mathrm{l})$ & $4.15(1.93)$ & $3.69(1.53)$ & $5.41(2.36)^{\mathrm{a}, \mathrm{b}}$ \\
\hline 17OHP4 (nmol/l) & $2.56(1.23)$ & $2.78(1.51)$ & $3.54(1.78)^{a, b}$ \\
\hline 17OHPE (nmol/l) & $4.98(4.15)$ & $5.19(4.33)$ & $6.67(5.50)^{d}$ \\
\hline Comp S (nmol/l) & $6.88(2.77)$ & $6.26(2.86)$ & $7.18(4.44)^{\mathrm{NS}}$ \\
\hline \multicolumn{4}{|l|}{$\mathrm{P} 450,17 \alpha$} \\
\hline 17,20 lyase $(\Delta 5)$ & $4.92(1.23)$ & $4.59(0.92)$ & $4.49(1.14)^{\mathrm{NS}}$ \\
\hline 17,20 lyase $(\Delta 4)$ & $2.17(0.15)$ & $2.10(0.12)$ & $3.11(0.29)^{\mathrm{a}, \mathrm{c}}$ \\
\hline 17-hydroxylase $(\Delta 4)$ & $2.24(1.54)$ & $3.14(2.73)$ & $2.90(2.28)^{\mathrm{b}, \mathrm{e}}$ \\
\hline 3ßHSD (A4/DHEA) & $0.36(0.22)$ & $0.41(0.25)$ & $0.68(0.44)^{a, b}$ \\
\hline 3ßHSD (17-OHP4/17-OHPE) & $0.98(0.17)$ & $1.02(0.46)$ & $0.98(0.38)^{N S}$ \\
\hline 21-Hydroxylase & $2.86(0.16)$ & $2.41(0.13)$ & $2.05(0.18)^{\mathrm{a}}$ \\
\hline 11-Hydroxylase & $53.14(2.26)$ & $53.37(2.28)$ & $56.43(7.86)^{\mathrm{NS}}$ \\
\hline F/17-OHP4 & $156.68(79.11)$ & $137.46(66.06)$ & $120.26(8.937)^{\mathrm{a}, \mathrm{d}}$ \\
\hline \multicolumn{4}{|c|}{ 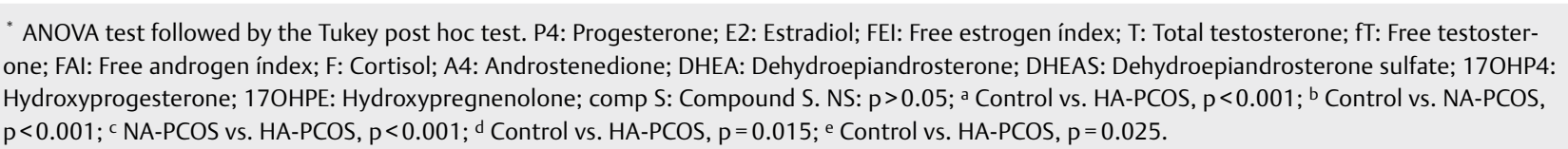 } \\
\hline
\end{tabular}

\section{Stepwise multiple regression}

The stepwise multiple regression models, including product-toprecursor ratios as criteria (dependent) variables and anthropometric parameters that showed significant simple correlation with these ratios as predictors (independency variables) are shown in - Table 5. In the NA-PCOS group, 17,20 lyase activity in the conversion of $17-\mathrm{OHPE}$ into DHEA ( $\triangle 5$ pathway) was facilitated by BMI and $L A P\left(\operatorname{Adj} R^{2}=0.106, t=2.179, p=0.033\right)$. In HA-PCOS patients, in the conversion of $17-\mathrm{OHP} 4$ into A4 ( $\triangle 4$ pathway), 17,20 lyase activity was positively favored by $F M\left(A d j R^{2}=0.029, t=2.175\right.$, $\mathrm{p}=0.032$ ). In controls, LAP was correlated with $\Delta 4$ pathway 17,20 lyase action (Adj $R^{2}=0.016, t=2.213, p=0.030$ ).

In controls, WC may facilitate the 17-hydroxylase activity in the conversion of P4 into 17-OHP4 (Adj $R^{2}=0.073, t=-2.608, p=$ $0.011)$. In NA-PCOS, 17 -hydroxylase, $\Delta 4$ pathway, was positively favored by WHtR (Adj $R^{2}=0.047, t=2.129, p=0.037$ ). In HA-PCOS, the activity of $3 \beta-H S D$ was influenced only by WHR ( $\operatorname{Adj} R^{2}=0.050$, $\mathrm{t}=2.878, \mathrm{p}=0.005)$ in the conversion of 17-OHPE into 17-OHP4. The activity of 21-hydroxylase was shown to be influenced only by LAP (Adj $\left.R^{2}=0.067, t=2.522, p=0.014\right)$ in normal controls. In PCOS patients, either normo-or hyperandrogenemic groups, anthropo- metric parameters did not influence either 21-hydroxylase or $11 \beta$-hydroxylase activities when a stepwise multiple regression model was applied.

\section{Discussion}

The association between hyperandrogenism and adipose tissue dysfunction, either in its amount or in its centralized distribution, is still debatable. Considering the high prevalence of obesity and hyperandrogenism in PCOS, the current study examined the impact of various anthropometric, proved markers of fat mass distribution, on corticosteroidogenic enzyme activities; secondarily, compared the levels of baseline sex-steroid and enzyme activities in NA-PCOS, HA-PCOS, and normal cycling women. Most anthropometric, metabolic and hormonal characteristics found in these groups confirmed previous reports [34,35]. Insulin levels showed different results between NA-PCOS and HA-PCOS and this seems to have clinical significance since insulin resistance is more frequent and intense in the HA-PCOS groups [36]. A positive correlation between some anthropometric parameters and $T$ concentration was demonstrated in HA-PCOS, indicating that high T levels leads to 
- Table 4 Simple correlations between anthropometric parameters and steroidogenic enzyme activities in normo- and biochemical hyperandrogenemic polycystic ovary syndrome and normal cycling women.

\begin{tabular}{|c|c|c|c|c|c|c|c|}
\hline $\begin{array}{l}\text { Adiposity } \\
\text { indicators }\end{array}$ & $\begin{array}{l}17,20 \text { Lyase (A5) } \\
\text { (DHEA / } \\
17-O H P E) r(p)\end{array}$ & $\begin{array}{l}\text { 12,20 Lyase (A4) } \\
\text { (A4/17-OHP4) } \\
\text { r (p) }\end{array}$ & $\begin{array}{l}\text { 17-Hydroxylase } \\
\text { (17-OHP4/P4) } \\
r \text { (p) }\end{array}$ & $\begin{array}{l}\text { 3ß-HSD II } \\
\text { (17-OHP4/17-OHPE) } \\
r(p)\end{array}$ & $\begin{array}{l}3 \beta-H S D ~ I I \\
\text { (A4/DHEA) } \\
r(p)\end{array}$ & $\begin{array}{l}\text { 21-Hydroxylase } \\
\text { (S/17-OHP4) } \\
r(p)\end{array}$ & $\begin{array}{l}\text { 11ß-Hydroxy- } \\
\text { lase }(F / S) r(p)\end{array}$ \\
\hline \multicolumn{8}{|l|}{ BMI $\left(\mathrm{kg} / \mathrm{m}^{2}\right)$} \\
\hline Controls & $-0.195(0.889)$ & $0.107(0.320)$ & $-0.197(0.076)$ & $0.015(0.886)$ & $-0.089(0.428)$ & $0.222(0.043)^{*}$ & $0.034(0.759)$ \\
\hline \multicolumn{8}{|l|}{ WHR } \\
\hline Controls & $-0.187(0.081)$ & $0.147(0.168)$ & $-0.095(0.393)$ & $-0.102(0.333)$ & $0.094(0.399)$ & $0.115(0.299)$ & $-0.291(0.006)^{*}$ \\
\hline HA-PCOS & $0.217(0.030)^{*}$ & $0.105(0.204)$ & $0.184(0.028)^{*}$ & $0.180(0.023)^{*}$ & $0.197(0.031)^{*}$ & $0.085(0.470)$ & $-0.083(0.346)$ \\
\hline \multicolumn{8}{|l|}{ WHtR } \\
\hline Controls & $-0.040(0.713)$ & $0.164(0.127)$ & $-0.207(0.062)$ & $-0.066(0.533)$ & $-0.022(0.045)^{*}$ & $0.252(0.021)^{*}$ & $-0.119(0.277)$ \\
\hline \multicolumn{8}{|l|}{ C Index } \\
\hline Controls & $-0.007(0.949)$ & $0.218(0.042)^{*}$ & $-0.242(0.030)^{*}$ & $-0.060(0.573)$ & $0.065(0.566)$ & $0.248(0.025)^{*}$ & $-0.249(0.023)^{*}$ \\
\hline NA-PCOS & $-0.294(0.012)^{*}$ & $-0.102(0.376)$ & $-0.062(0.599)$ & $-0.196(0.078)$ & $-0.018(0.832)$ & $-0.009(0.940)$ & $-0.130(0.291)$ \\
\hline HA-PCOS & $-0.294(0.012)^{*}$ & $-0.102(0.376)$ & $-0.062(0.599)$ & $-0.196(0.078)$ & $-0.018(0.882)$ & $-0.009(0.940)$ & $-0.130(0.291)$ \\
\hline \multicolumn{8}{|l|}{ FM } \\
\hline HA-PCOS & $0.055(0.589)$ & $0.212(0.010)^{*}$ & $-0.037(0.662)$ & $0.048(0.549)$ & $0.117(0.207)$ & $0.028(0.749)$ & $-0.009(0.916)$ \\
\hline \multicolumn{8}{|l|}{ LBM/FM } \\
\hline HA-PCOS & $-0.041(0.683)$ & $0.231(0.005)^{*}$ & $-0.067(0.429)$ & $0.098(0.217)$ & $-0.106(0.251)$ & $-0.014(0.868)$ & $-0.071(0.423)$ \\
\hline \multicolumn{8}{|l|}{ VAI } \\
\hline Controls & $-0.061(0.584)$ & $0.247(0.026)^{*}$ & $-0.105(0.765)$ & $-0.162(0.136)$ & $-0.092(0.421)$ & $0.153(0.185)$ & $-0.142(0.212)$ \\
\hline NA-PCOS & $-0.319(0.006)^{*}$ & $0.058(0.616)$ & $0.104(0.378)$ & $-0.277(0.012)^{*}$ & $-0.024(0.843)$ & $0.033(0.782)$ & $0.154(0.214)$ \\
\hline HA-PCOS & $-0.319(0.016)^{*}$ & $0.058(0.616)$ & $0.104(0.378)$ & $-0.277(0.012)^{*}$ & $-0.024(0.843)$ & $0.033(0.782)$ & $0.154(0.214)$ \\
\hline \multicolumn{8}{|l|}{ LAP } \\
\hline Controls & $-0.076(0.496)$ & $0.237(0.031)^{*}$ & $-0.143(0.216)$ & $-0.129(0.233)$ & $-0.027(0.813)$ & $0.264(0.020)^{*}$ & $-0.137(0.227)$ \\
\hline NA-PCOS & $-0.312(0.008)^{*}$ & $0.121(0.293)$ & $0.021(0.856)$ & $-0.198(0.074)$ & $0.182(0.134)$ & $0.055(0.640)$ & $0.013(0.919)$ \\
\hline HA-PCOS & $-0.267(0.023)^{*}$ & $0.118(0.304)$ & $-0.024(0.838)$ & $-0.114(0.310)$ & $0.067(0.583)$ & $0.216(0.065)$ & $0.010(0.934)$ \\
\hline
\end{tabular}

visceral adiposity $[37,38]$. Otherwise, a negative correlation between A4 and DHEA with a few anthropometric markers was found in this hyperandrogenemic group. In NA-PCOS group, and in controls, 17-OHPE was also negatively correlated with VAI and LAP. In normal cycling controls, 17-OHP4 showed positive correlation with FM and VAI.

As to the enzyme activities, the 17,20 lyase ( $\Delta 5$ pathway) was negatively correlated with lipids and central obesity in both groups of PCOS patients. Similarly, the activity of $3 \beta$-HSD enzyme was negatively correlated with VAl in both PCOS groups. Applying a multivariate stepwise regression, the activity of 17,20 lyase ( $\triangle 5$ pathway) was influenced by BMI and LAP in NA-PCOS women. In HAPCOS group, 17,20 lyase ( $\triangle 4$ pathway) was enabled by FM. The $3 \beta$-HSD activity, in the conversion of 17-OHPE into 17-OHP4, was correlated with WHR. However, the activity of $3 \beta$-HSD in the conversion of DHEA into A4 was not influenced by any anthropometric surrogates, in any group of patients.

A few points should be considered as possible weaknesses of the current results. The cross-sectional design of this study does not prove a direct causality for the examined correlations. Anthropometric measures might be less sensitive and accurate when com- pared to DEXA, CT or MRI in quantifying fat deposition, but their general usability must be considered. Furthermore, in clinical settings anthropometric measurement is a more cost-effective and feasible method for measuring body composition, and provides comparable estimates of fat tissue [39]. Therefore, the use of anthropometric parameters as surrogates for adipose tissue distribution in PCOS is largely accepted in most clinical studies [40-43]. The use of product-to-precursor ratio instead of a molecular biology technique to examine enzymatic activity must also be considered in clinical studies. The hormone levels measured are the net of production and degradation at a given moment, but both precursor and product may be changed after cell secretion. Markers of adipocyte function or dysfunction were not measured in the blood for direct comparison, however some anthropometric parameters have already been associated with the concentrations of a number of adipocyte products [44-47]. Despite these weaknesses, the current study has multiple scientific strengths. It included a number of patients who were carefully and prospectively evaluated. Furthermore, the present study added many novel insights to the complex relationship between total body fat, body shape, fat distribution, and steroidogenic enzyme activity. Secondarily, verified 
- Table 5 Multivariate stepwise regression correlating anthropometric adiposity indicators with steroidogenic enzyme activities in normo- and biochemical hyperandrogenemic PCOS and normal cycling women.

\begin{tabular}{|c|c|c|c|c|c|c|c|c|c|}
\hline Dependent variables & $\begin{array}{l}\text { Adiposity } \\
\text { predictors }\end{array}$ & $\mathbf{R}$ & $\mathbf{R}^{2}$ & $\begin{array}{l}\text { Adjusted } \\
\mathbf{r}^{2}\end{array}$ & $\begin{array}{l}\text { Standard error } \\
\text { estimate }\end{array}$ & $\begin{array}{l}\text { Durbin- } \\
\text { Watson }\end{array}$ & $\begin{array}{l}\text { Standardized } \\
\text { Beta coefficient }\end{array}$ & $\mathbf{t}$ & P \\
\hline \multicolumn{10}{|c|}{ DHEA/17-OHPE (constant) } \\
\hline NA-PCOS & BMI, LAP & 0.362 & 0.131 & 0.106 & 4.6501 & 2.074 & 0.283 & 2.179 & 0.033 \\
\hline \multicolumn{10}{|l|}{ A4/17-OHP4 (constant) } \\
\hline Controls & LAP & 0.242 & 0.058 & 0.046 & 1.1695 & 1.984 & 0.242 & 2.213 & 0.030 \\
\hline HA-PCOS & FM & 0.190 & 0.036 & 0.029 & 2.21757 & 1.885 & 0.190 & 2.175 & 0.032 \\
\hline \multicolumn{10}{|l|}{ 17-OHP4/P4 (Constant) } \\
\hline Controls & WC & 0.292 & 0.085 & 0.073 & 1.3361 & 2.108 & -0.292 & -2.608 & 0.011 \\
\hline NA-PCOS & WHtR & 0.245 & 0.060 & 0.047 & 2.6851 & 1.743 & 0.245 & 2.129 & 0.037 \\
\hline \multicolumn{10}{|c|}{ 17-OHP4/17-OHPE (Constant) } \\
\hline HA-PCOS & WHR & 0.240 & 0.057 & 0.050 & 1.8732 & 1.427 & 0.240 & 2.878 & 0.005 \\
\hline \multicolumn{10}{|l|}{ S/17-OHP4 (constant) } \\
\hline Controls & LAP & 0.281 & 0.079 & 0.067 & 1.2464 & 1.755 & 0.281 & 2.522 & 0.014 \\
\hline
\end{tabular}

baseline sex-steroid concentrations and adiposity relationship in PCOS patients, with either normal or higher levels of androgen.

Visceral adipose tissue (WAT) differentiation, proliferation, abdominal centralization, and hypertrophy are driven by testosterone levels [48-51]. Adrenal androgens were already found to correlate with adipose tissue in hyperandrogenemic states [52]. The finding of positive correlation between $\mathrm{T}$, fat mass, and waist circumference/height ratio in HA-PCOS are consistent with the results of other reports that have previously demonstrated to exist association between T, FM [7, 18] and WHR [53]. DHEA was shown to be positively correlated with general body fat mass [40] but the negative correlation between DHEA and WHR in NA-PCOS indicates that the synthesis of this precursor may be diminished in the presence of central adiposity. On the other hand DHEA was already shown to be negatively correlated with visceral adiposity [11]. Interleukin-6 (IL-6), a product of adipocytes with a higher level of expression in PCOS, was shown to increase DHEA syntheses and secretion [54]. It is not clear whether this adipokine increased the activity of the enzyme P450 $17 \alpha$ in the $\Delta 5$ pathway. The negative correlation of A4 with some adiposity markers in NA-PCOS, and with LBM in HA-PCOS suggest that adiposity may worsen A4 syntheses, probably because leptin and adiponectin may downregulate the expression of steroidogenic enzymes $[12,55]$. In a few studies, A4 was positively correlated with WHR [10] and FM [40]. The mechanisms behind these associations are not totally clear, but may involve lower activity of $3 \beta-H S D$ in the conversion of DHEA into $A 4$ or higher 17,20 lyase activity in the $\Delta 4$ pathway.

Adiponectin was shown to decrease A4 syntheses in bovine theca cells in vitro [14]. Furthermore, the acute administration of adiponectin was demonstrated to decrease A4 secretion [56]. Their findings explain the lower levels of adiponectin and the higher levels of A4 in PCOS subjects. The negative simple correlation between adiposity markers and concentrations of 17-OHPE in HA-PCOS groups strongly indicates that adiposity may diminish its secretion.
Otherwise, VAI, and LAP were reported to be positively correlated with 17-OHPE in NA-PCOS patients [34].

The regulation of the steroidogenic enzyme activities in adrenal and ovaries are complex and not completely understood. The adipose tissue products impact on corticosteroidogenic enzymes need to be characterized. A relationship between plasma concentrations of adipokines and body fat distribution was recently demonstrated [57]. Despite the current study did not measure directly any adipokine products, most of the anthropometric measured in the current study are proven surrogates of the presence of abdominal visceral adiposity. It is known that the adipose tissue is involved in the regulation of glucocorticoid metabolism, via $11 \beta$-hydroxysteroid dehydrogenase $[54,58]$. In addition, adipocyte products control the ovarian function [59], via a bidirectional communication between certain adipokines and granulosa and theca cells [60-62]. In fact, it was already demonstrated that receptors for leptin, adiponectin, TNF $\alpha$, and IL-6, are expressed both in theca and granulosa ovarian cells [63].

Abdominal anthropometric parameters have already been associated with adipocyte dysfunction and abnormal secretion of adipokines and inflammatory markers [57,64-69]. The positive correlation between WHR and 17,20 lyase $(\Delta 5)$ in HA-PCOS indicated the influence of central obesity in the activity of this enzyme. However, in an early study the activity of this enzyme was higher in NAPCOS and controls [35]. Taking into account both studies, 17,20 lyase $(\Delta 5)$ activity was lower in both groups of PCOS when compared to controls [3]. The mechanism explaining the positive correlation between WHR and 17,20 lyase $(\Delta 5)$ activity is not clear. It is possible that local estradiol, higher in hyperandrogenic states, may activate this enzyme [70]. Further leptin, and IL-6 may also increase 17,20 lyase activity $[71,72]$. The hyperinsulinemic state may also activate the expression of 17,20 lyase [73].

The negative correlation between 17,20 lyase, via $\Delta 5$, and $\mathrm{Cl}$, $\mathrm{VAI}$, and LAP in both NA-PCOS and HA-PCOS groups may reflect the down-regulated effect of leptin in adrenal cells $[47,74]$. In non- 
PCOS controls, 17,20 lyase activity was not influenced by any anthropometric parameter in the current study. In HA-PCOS, women the increased 17,20 lyase activity in the $\Delta 4$ pathway corroborates previously in vitro and in vivo studies [35]. The positive correlations between 17,20 lyase ( $\Delta 4$ pathway) activity with adipose tissue in NA-PCOS and HA-PCOS support a previous observation [34] and suggest that an undefined adipocyte marker activates this enzyme in this pathway. Interestingly, there were positive correlation of 17,20 lyase $(\Delta 4)$ with $\mathrm{Cl}, \mathrm{VAI}$, and LAP in normal cycling women.

The positive correlation of WHR with 17-hydroxylase activity in HA-PCOS may reflect the resistin action on the activity of this enzyme $[72,75]$. This effect was already demonstrated in ovarian and theca cells of polycystic ovaries [75]. Resistin was also associated with BMI in PCOS women [76]. Similar activity of 17-hydroxylase in PCOS and non-PCOS subjects was also reported [75]. The negative correlation of 17-hydroxylase with $\mathrm{Cl}$ in normal cycling women may reflect the leptin action on the activity of this enzyme [73]. As to the $3 \beta$-HSD activity, it was found that it tended to be higher in the HA-PCOS group. On the other hand, decreased activity of this enzyme in both NA-PCOS and HA-PCOS was reported by others $[77,78]$. In the conversion of 17-OHPE into 17-OHP4 the activity of $3 \beta-\mathrm{HSD}$ is inversely correlated with androgen production [75]. In the present study WHR showed positive correlation with 3 $\beta$-HSD activity in HA-PCOS. On the other hand the activity $3 \beta-H S D$ was negatively correlated with VAI in both NA-PCOS and HA-PCOS, probably by the inhibitory action of leptin in adrenal gland [55]. The WHR was positively correlated with $3 \beta-H S D$ activity in the conversion of DHEA into A4 in HA-PCOS but, in controls, this correlation was negative. A possible role of resistin in this enzyme action was reported [75].

The activity of 21-hydroxylase did not correlate with any anthropometric parameter in both PCOS groups, supporting previous observation $[34,41]$. The finding that the activity of 21 -hydroxylase positively correlated with adiposity indicators in normal cycling controls is novel but still unclear. No anthropometric parameter influenced the combined 21-hydroxylase and 11-hydroxylase activities in PCOS patients in the current study, and no study reporting on this matter was found for comparisons. The negative correlation of $11 \beta$-hydroxylase activity with abdominal obesity markers in normal controls in the present study partially corroborates previous findings [34].

After multiple regression analysis BMI and LAP were predictive of 17,20 lyase $(\Delta 5)$ activity in the NA-PCOS group, indicating that the hyperandrogenemic state itself does not modulate the action of this enzyme. However, total body mass and the lipid accumulation may increase its activity. The adipocyte mediator which could be involved in 17,20 lyase activity ( $\Delta 5$ pathway) is not clear at the moment. In the $\Delta 4$ pathway, 17,20 lyase activity was influenced by LAP in non-PCOS women, and by FM in the HA-PCOS group. Interestingly, WHR predicted the $3 \beta$-HSD activity in HA-PCOS, conversion of 17-OHPE into 17-OHP4. Though the results of the present study could not be compared to any previous report, they, even that indirectly, indicate that the steroidogenic enzymes activities are largely modulated by adiposity in PCOS women. Mainly, enabling a higher and undesirable androgen production. Even though the clinical implications are not clear, these findings support the knowledge lounge that in PCOS women, abnormal fat mass distribution facilitates androgen production, worsening their prognoses.

\section{Conclusions}

Finally, and in addition to the actual knowledge, the present study demonstrated that in HA-PCOS women the 17,20 lyase ( $\Delta 4$ pathway) activity is positively associated with FM, and FM/LBM ratio, but not related with the conicity index. This observation suggests that fat mass as a whole and not its distribution in the body influences 17,20 lyase ( $\Delta 4$ ) activity; yet in HA-PCOS, $\Delta 5$ pathway, the activity 17,20 lyase was associated with WHR and negatively with IC, VAI, and LAP. The 3 $\beta$-HSD activity, both in the conversion of 17 OHPE into 17-OHP4 and DHEA into A4, was predicted by WHR and total BW.

In NA-PCOS group, 17,20 lyase $(\Delta 5)$ was negatively associated with IC, VAI, and LAP and the $3 \beta-H S D$ is negatively influenced by VAI. Therefore, anthropometric parameters, in both HA-PCOS and NA-PCOS, have different impact on steroidogenic enzyme activities. Nevertheless, the clinical implications of those findings need further investigation. Future studies aiming to analyze the intimate relationship between adipocyte-steroidogenic cells using either basic or clinical designs are needed. Based on this scenery, it is not possible at this time, to tailor any new measures to benefit the overweight or obese PCOS women in addition to lifestyle modification.

\section{Acknowledgements}

The authors are grateful to American Journal of Experts for English revision.

\section{Conflict of Interest}

The authors declare that they have no conflict of interest.

References

[1] Zore T, Joshi NV, Lizneva D et al. Polycystic ovarian syndrome: Long-term health consequences. Semin Reprod Med 2017; 35: $271-281$

[2] Wabitsch $\mathrm{M}$, Hauner $\mathrm{H}$, Heinze $\mathrm{E}$ et al. Body fat distribution and steroid hormone concentrations in obese adolescent girls before and after weight reduction. J Clin Endocrinol Metab 1995; 80: 3469-3475

[3] Ezeh U, Pall M, Mathur R et al. Association of fat to lean mass ratio with metabolic dysfunction in women with polycystic ovary syndrome. Hum Reprod 2014; 129: 1508-1517

[4] Elbers JM, Asscheman $\mathrm{H}$, Seidell JC et al. Long-term testosterone administration increases visceral fat in female to male transsexuals. J Clin Endocrinol Metab 1997; 82: 2044-2047

[5] Sung YA, Oh JY, Chung $\mathrm{H}$ et al. Hyperandrogenemia is implicated in both the metabolic and reproductive morbidities of polycystic ovary syndrome. Fertil Steril 2014; 101: 840-845

[6] Akopians AL, Madrigal V, Fisch S et al. Hyperandrogenism is associated with preferential fat deposition of visceral versus subcutaneous (SC) abdominal fat in lean polycystic ovary syndrome (PCOS) women. Fertil Steril 2016; 106: e31. ASRM Abstracts O-79

[7] Carmina E, Bucchieri S, Esposito A et al. Abdominal fat quantity and distribution in women with polycystic ovary syndrome and extent of its relation to insulin resistance. J Clin Endocrinol Metab 2007; 92: 2500-2505 
[8] Bil E, Dilbaz B, Cirik DA et al. Metabolic syndrome and metabolic risk profile according to polycystic ovary syndrome phenotype. J Obstet Gynaecol Res 2016; 4: 837-843

[9] Knudsen KL, Blank SK, Burt Solorzano C et al. Hyperandrogenemia in obese peripubertal girls: Correlates and potential etiological determinants. Obesity 2010; 18: 2118-2124

[10] Nada Z. Which is more reliable in polycystic ovarian syndrome: Body mass index or waist hip ratio? Int J Sci: Basic Appl Res 2010; 24: 283-290

[11] Keller JL, Casson PR, Toth MJ. Relationship of androgens to body composition, energy and substrate metabolism and aerobic capacity in healthy, young women. Steroids 2011; 76: 1247-1251

[12] Lagaly DV, Aad PY, Grado-Ahuir JA et al. Role of Adiponectin in regulating ovarian theca and granulosa cell function. Mol Cell Endocrinol 2008; 284: 38-45

[13] Smolinska N, Dobrzyn K, Kiezun M et al. Effect of Adiponectin on the steroidogenic acute regulatory protein P450 side chain cleavage enzyme and 3ß-hydroxysteroid dehydrogenase gene expression, progesterone and androstenedione production by the porcine uterus during early pregnancy. J Physiol Pharmacol 2016; 67: 443-456

[14] Comim FV, Hardy K, Franks S. Adiponectin and its receptors in the ovary: further evidence for a link between obesity and hyperandrogenism in polycystic ovary syndrome. PLoS One 2013; 8: e80416

[15] Douchi T, Huin H, Nakamura $S$ et al. Body fat distribution in women with polycystic ovary syndrome. Obstet Gynecol 1995; 86: 516-519

[16] Deslypere JP, Verdonck L, Vermeulen A. Fat tissue: A steroid reservoir and site of steroid metabolism. J Clin Endocrinol Metab 1985; 61: 564-570

[17] Bolt HM, Gobel P. Formation of estrogens from androgens by human subcutaneous adipose tissue in vitro. Horm Metab Res 1972; 4: 312-313

[18] Bleau G, Roberts KD, Chapdelaine A. The in vitro uptake and metabolism of steroids in human adipose tissue. J Clin Endocrinol Metab 1974; 39: 236-246

[19] Szymczak J, Milewicz A, Thijssen JHH et al. Concentrations of sex steroids in adipose tissue after menopause. Steroids 1998; 63: 319-321

[20] Simpson AM, Judd S], Rodgers RJ. Role of aromatase in sex steroid action. J Mol Endocrinol 2000; 25: 149-156

[21] Masuzaki H, Paterson J, Shinyama $\mathrm{H}$ et al. A transgenic model of visceral obesity and the metabolic syndrome. Science 2001; 294: 2166-2170

[22] Yildiz BO, Gedik O. Insulin resistance in polycystic ovary syndrome: hyperandrogenemia versus normoandrogenemia. Eur J Obstet Gynecol Reprod Biol 2001; 100: 62-66

[23] Azziz R, Woods KS, Reyna R et al. The prevalence and features of the polycystic ovary syndrome in an unselected population. J Clin Endocrinol Metab 2004; 89: 2745-2749

[24] de Medeiros SF, Barbosa JS, Yamamoto MMW. Comparison of steroidogenic pathways among normoandrogenic and hyperandrogenic polycystic ovary syndrome patients and normal cycling women. J Obstet Gynaecol Res 2015; 41: 254-263

[25] de Medeiros SF, Ormond CM, de Medeiros MAS et al. Metabolic and endocrine connections of 17-hydroxypregnenolone in polycystic ovary syndrome women. Endocr Connect 2017; 6: 479-488

[26] James WPT. Research on obesity. A repot of the DHSS/MRC group. Her Majesty's Stationary. Department of Health and Social Security and Medical Research Council Group. In: Her Majesty’s Stationary Office. London: Office; 1976; 94

[27] Valdez R. A simple model-based index of abdominal adiposity. ] Clin Epidemiol 1991; 44: 955-956

[28] Amato MC, Giordano C. Visceral adiposity index: An indicator of adipose tissue dysfunction. Int J Endocrinol 2014; 3: 730827
[29] Kahn HS, Valdez R. Metabolic risks identified by the combination of enlarged waist and elevated triacylglycerol concentration. Am J Clin Nutr 2003; 78: 928-934

[30] Friedewald WT, Levy RI, Fredrickson DS. Estimations of the concentration of low-density lipoprotein cholesterol in plasma, without use of the preparative ultracentrifuge. Clin Chem 1972; 18: 499-502

[31] Geloneze B, Vasques AC, Stabe CF et al. BRASMS Investigators, HOMA1-IR and HOMA2-IR indexes in identifying insulin resistance and metabolic syndrome: Brazilian Matabolic Syndrome Sudy (BRAMS). Arq Bras Endocrinol Metab 2009; 53: 281-287

[32] Diabetes Trial Unit. The Oxford Centre for Diabetes, Endocrinology and Metabolism [internet]. Oxford, UK: Oxford University. 2013; May 1 Available at: http://www.dtu.ox.ac.uk/homacalculator

[33] de Medeiros SF, Ormond CM, de Medeiros MAS et al. Metabolic and endocrine connections of 17-hydroxypregnenolone in polycystic ovary syndrome women. Endoc Connect 2017; 6: 479-488

[34] Sowers SM, Derby C, Jannausch ML et al. Insulin resistance, hemostatic factors, and hormone interactions in pre- and perimenopausal women: SWAN. J Clin Endocrinol Metab 2003; 88: 4904-4910

[35] de Medeiros SF, Barbosa JS, Yamamoto MMW. Comparison of steroidogenic pathways among normoandrogenic and hyperandrogenic polycystic ovary syndrome patients and normal cycling women. J Obstet Gynaecol Res 2015; 41: 254-263

[36] Baptiste CG, Marie-Claude B, Trottier A et al. Insulin and hyperandrogenism in women with polycystic ovary syndrome. J Steroid Biochem Mol Biol 2010; 122: 42-52

[37] Albu A, Florea S, Fica S. The connections between androgens and adipose tissue function in polycystic ovary syndrome patients. Int J Sciences Appl Research 2014; 15: 368-378

[38] Yang R, Yang S, Li R et al. Effects of hyperandrogenism on metabolic abnormalities in patients with polycystic ovary syndrome: A meta-analysis. Reprod Biol Endocrinol 2016; 14: 67

[39] Wang JG, Zhang Y, Chen HE et al. Comparison of two bioelectrical impedance analysis devices with dual energy $\mathrm{X}$-ray absorptiometry and magnetic resonance imaging in the estimation of body composition. J Strength Cond Res 2013; 27: 236-243

[40] Hicks R, Yee JK, Mao CS et al. Precursor-to-product ratios reflect biochemical phenotype in congenital adrenal hyperplasia. Metabolomics 2014; 10: 123-131

[41] de Medeiros SF, Gil-Junior AB, Barbosa JS et al. New insights into steroidogenesis in normo-and hyperandrogenic polycystic ovary syndrome patients. Arq Bras Endocrinol Metab 2013; 57: 437-444

[42] Costa-Barbosa FA, Carvalho VM, Nakamura OH et al. Zona fasciculata 21-hydroxysteroids and precursor-to-product ratios in 21- hydroxylase defiency: Further characterization of classic and non-classic patients and heterozygote carriers. J Endocrinol Invest 2011; 34: 587-592

[43] Tieh PY, Yee JKW, Hicks RA et al. Utility of a precursor-to-product ratio in the evaluation of presumptive positives in newborn screening of congenital adrenal hyperplasia. J Perinatol 2017; 37: 283-287

[44] Ardawi MS, Rouzi AA. Plasma adiponectin and insulin resistance in women with polycystic ovary syndrome. Fertil Steril 2005; 83: 1708-1716

[45] Mannerås-Holm L, Leonhardt H, Kullberg J et al. Adipose tissue has aberrant morphology and function in PCOS: Enlarged adipocytes and low serum adiponectin, but not circulating sex steroids, are strongly associated with insulin resistance. J Clin Endocrinol Metab 2011; 96 : E304-E311

[46] Chen X, jia X, Qiao J et al. Adipokines in reproductive function: A link between obesity and polycystic ovary syndrome. J mol Endocrinol 2013; 50: R21-R37

[47] Kim SH, Moon JY, Sasano H et al. Body fat mass is associated with ratio of steroid metabolites reflecting 17, 20-lyase activity in prepubertal girls. J Clin Endocrinol Metab 2016; 101: 4653-4660 
[48] Dieudonne MN, Pecquery R, Boumediene A. Androgen receptors in human preadipocytes and adipocytes: Regional specificities and regulation by sex steroids. Am J Physiol 1998; 274: 1645-1652

[49] Carbould A. Chronic testosterone treatment induces selective insulin resistance in subcutaneous adipocytes of women. J Endocrinol 2007; 94: $157-163$

[50] Chazenbalk G, Singh P, Irge D et al. Androgens inhibit adipogenesis during human adipose stem cell commitment to preadipocyte formation. Steroids 2013; 78: 920-926

[51] Barbosa-Desongles A, Hernández C, Simó R et al. Testosterone induces cell proliferation and cell cycle gene overexpression in human visceral preadipocytes. Am J Physiol Cell Physiol 2013; 305: C355-C359

[52] Evans DJ, Barth JH, Burke CW. Body fat topography in women with androgen excess. Int J Obes 1988; 12: 157-162

[53] Van Anders SM, Hampson E. Waist-to-hip ratio is positively associated with bioavailable testosterone but negatively associated with sexual desire in healthy premenopausal women. Psychosom Med 2005; 67: 246-250

[54] Judd AM, Call GB, Barney M et al. Possible function of IL-6 and THF as intraadrenal factors in the regulation of adrenal steroid secretion. Ann NY Acad Sci 2000; 917: 628-637

[55] Kruse M, Bornstein SR, Uhlmann K et al. Leptin down-regulates the steroid producing system in the adrenal. Endocr Res 1998; 24: 587-590

[56] Schrover IM, Van der Graaf Y, Spiering W et al. The relation between body fat distribution, plasma concentrations of adipokines and the metabolic syndrome in patients with clinically manifest vascular disease. Eur J Prev Cardiol 2018; 25: 1-10

[57] Bayoumy HA, Alothman AN. Adrenal contribution to polycystic ovary syndrome. Med Princ Prac 2001; 10: 151-155

[58] Rask E, Walker BR, Söderberg $S$ et al. Tissue-specific changes in peripheral cortisol metabolism in obese women: Increased adipose 11beta-hydroxysteroid dehydrogenase type 1 activity. J Clin Endocrinol Metab 2002; 87: 3330-3336

[59] Campos DB, Palin MF, Bordignon V et al. The 'beneficial' adipokines in reproduction and fertility. Int J Obes (Lond) 2008; 32: 223-231

[60] Agarwal SK, Vogel K, Weitsman SR et al. Leptin antagonizes the insulin-like growth factor-I augmentation of steroidogensis in granulosa cells of the human ovary. J Clin Endocrinol Metab 1999; 84: 1072-1076

[61] Brann DW, Wade MF, Dhandapani KM et al. Leptin and reproduction. Steroids 2002; 67: 95-104

[62] Binelli M, Murphy BD. Coordinated regulation of follicle development by germ and somatic cells. Reprod Fertil Dev 2010; 22: 1-12

[63] Samir M, Glister C, Mattar D et al. Follicular expression of pro-inflammatory cytokines tumour necrosis factor- $\alpha$ (TNF $\alpha$ ), interleukin 6 (IL6) and their receptors in cattle: TNF $\alpha$, IL6 and macrophages suppress thecal androgen production in vitro. Reproduction 2017; 154: 35-49
[64] Cupisti S, Kajaia N, Dittrich R et al. Body mass index and ovarian function are associated with endocrine and metabolic abnormalities in women with hyperandrogenic syndrome. Eur J Endocrinol 2008; 158: 711-719

[65] Pangaribuan B, Yusuf I, Mansyur M et al. Serum adiponectin and resistin in relation to insulin resistance and markers of hyperandrogenism in lean and obese women with polycystic ovary syndrome. Therap Adv Endocrinol Metab 2011; 2: 235-245

[66] Lecke SB, Mattei F, Morsch DM, Spritzer PM. Abdominal subcutaneous fat gene expression and circulating levels of leptin and adiponectin in polycystic ovary syndrome. Fertil Steril 2011; 95: 2044-2049

[67] Villa J, Pratley RE. Adipose tissue dysfunction in polycystic ovary syndrome. Curr Diab Rep 2011; 11: 179-184

[68] Barber TM, Franks S. Adipocyte biology in polycystic ovary syndrome. Mol Cell Endocrinol 2013; 373: 68-76

[69] Goossens GH. The metabolic phenotype in obesity: Fat mass, body fat distribution, and adipose tissue function. Obes Facts 2017; 10: 207-215

[70] Ditkoff EC, Fruzzetti F, Chang L et al. The impact of estrogen on adrenal androgen sensitivity and secretion in polycystic ovary syndrome. J Clin Endocrinol Metab 1995; 80: 603-607

[71] Path G, Bornstein SR, Ehrhart-Bornstein $M$ et al. Interleukin-6 and the interleukin-6 receptor in the human adrenal gland: Expression and effects on steroidogenesis. J Clin Endocrinol Metab 1997; 82: 2343-2349

[72] Biason-Lauber A, Zachmann M, Schoenle E]. Effect of leptin on CYP17 enzymatic activities in human adrenal cells: new insight in the onset of adrenarche. Endocrinology 2000; 141: 1446-1454

[73] Auchus RJ, Lee TC, Miller WL. Cytochrome b5 augments the 17,20-lyase activity of human P450c17 without direct electron transfer. J Biol Chem 1998; 273: 3158-3165

[74] Ryan KJ, Petro Z. Steroid biosynthesis by human ovarian granulosa and thecal cells. J Clin Endocrinol Metab 1966; 26: 46-52

[75] Munir I, Yen HW, Baruth T et al. Resistin stimulation of 17alpha-hydroxylase activity in ovarian theca cells in vitro: relevance to polycystic ovary syndrome. J Clin Endocrinol Metab 2005; 90: 4852-4857

[76] Yilmaz M, Bukan N, Demirci H et al. Serum resistin and adiponectin levels in women with polycystic ovary syndrome. Gynecol Endocrinol 2009; 25: 246-252

[77] Rosenfield RL, Barnes RB, Cara JF et al. Dysregulation of cytochrome P450c 17 alpha as the cause of polycystic ovarian syndrome. Fertil Steril 1990; 53: 785-791

[78] Shi L, Wudy SA, Buyken AE et al. Body fat and animal protein intakes are associated with adrenal androgen secretion in children. Am J Clin Nutr 2009; 90: 1321-1328 